\title{
A Quadra Invictus: Projeto de Habitação Social participativo e mais sustentável ${ }^{1}$
}

\section{The Invictus Block: participative and sustainable Project}

\author{
Rangel, Mateus Marques'; Andrade, Liza Maria Souza de² \\ 1 Universidade de Brasília, marqueszmateus@gmail.com \\ 2 Universidade de Brasília
}

\begin{abstract}
RESUMO
Este trabalho apresenta o processo de projeto participativo de habitação social para a Quadra Invictus, localizada na ocupação Dorothy Stang, em Sobradinho - Distrito Federal com o objetivo de demonstrar, através de um trabalho fina de graduação ainda em desenvolvimento, as soluções parciais com foco em estratégias sustentáveis, e também propõe tipologias habitacionais desenvolvidas a partir da participação da população local. Trata-se de um trabalho de extensão do Grupo de Pesquisa e Extensão Periférico da FAU/UnB no contexto do Edital $n^{\circ}$ 1/2017 DEX/DPI fundamentado nas Dimensões da Sustentabilidade (ambiental, social, econômica e cultural), que possibilitaram realizar com a população oficinas participativas que abordassem desde o diagnóstico da situação inicial até as propostas para o urbanismo e tipologias arquitetônicas. A sistematização dos resultados das oficinas permitiu obter dados emergentes da população e 3 tipos de habitação: sobrado, esquina e uso misto. Como resultado da proposta-síntese obteve-se a adaptação da quadra às curvas de nível com vegetação nativa e os pontos afetivos marcados pelos moradores, adensamento por meio da criação de agrupamentos de lotes, habitações voltadas para as ruas, quintais compartilhados e alargamento das calçadas para propiciar o encontro das pessoas.
\end{abstract}

Palavras-chave: Dorothy Stang, processo participativo, habitação social.

\begin{abstract}
This work presents the participatory social housing project for the Invictus Block, located in the occupation named Dorothy Stang, in Sobradinho - Distrito Federal. It aims to demonstrate, through a fine work of graduation still under development, partial solutions focused in sustainable strategies, and also proposes housing tipologies from the participation of the local population. This is an extension work by the Extension and Research Group from FAU/UnB in the context context of Decree 1/2017 DEX / DPI based on the Andrade and Lemos (2015) Sustainability Dimensions, environmental, social, economic and cultural, which made it possible to carry out participatory workshops with the population, ranging from the diagnosis of the initial situation to the proposals for urban planning and architectural typologies. The systematization results of workshops allowed to obtain emerging data from the population and

${ }^{1}$ RANGEL, Mateus Marques; ANDRADE, Liza Maria Souza de. A Quadra Invictus: Projeto de Habitação Social participativo e mais Sustentável. In: II SIMPÓSIO NACIONAL DE GESTÃO E ENGENHARIA URBANA: SINGEURB, 2019, São Paulo. Anais... Porto Alegre: ANTAC, 2019.
\end{abstract}


3 types of housing: tew-story house, corner house and mixed use house. As a result of the proposal-synthesis the adaptation of the block to the topography with native vegetation and the affective points marked by the residents was achieved, by means of the creation of groupings of lots, houses facing the streets, shared backyards and widening of the sidewalks to enable people to meet up.

Keywords: Dorothy Stang, participatory process, social housing.

\section{INTRODUÇÃO}

Este trabalho tem como objetivo demonstrar o processo de projeto de habitação social participativo da Quadra Invictus da ocupação Dorothy Stang, localizada no Distrito Federal. Tal trabalho é derivado do projeto de pesquisa-ação "O cantinho de todos: o desenho urbano socioecológico do Dorothy Stang à mão de seus ocupantes" do Grupo de Pesquisa e Extensão "Periférico, trabalhos emergentes" e pelo Escritório Modelo CASAS da Faculdade de Arquitetura e Urbanismo da Universidade de Brasília, no contexto do edital n 01/2017 (DEXDPI), no qual está sendo desenvolvido uma proposta de urbanismo participativo

No sentido de dar continuidade à pesquisa do grupo e de explorar soluções mais sustentáveis e emergentes para a comunidade, decidiu-se detalhar a quadra nomeada como "Invictus". O projeto do qual trata este trabalho teve a intenção de envolver a comunidade em todas as fases do processo, inspirado em metodologias e ferramentas de projeto como os padrões de Alexander et al. (1977), os padrões dos ecossistemas urbanos de Andrade (2014) e das dimensões da sustentabilidade de Andrade e Lemos (2015).

Os patterns (ou padrões), segundo Barros (2011), são uma rede de conceitos, parâmetros e padrões de acontecimentos que são identificados através da observação in loco; integram a escala humana e a vivacidade urbana, de maneira que não podem ser dissociados, isto é, sem entender a inter-relação existente entre o local e os seus diversos padrões que já se encontram no próprio lugar. Acredita-se que os padrões de Alexander et al. (1977) formam uma perspectiva ecológica humana e ampla, considerando as várias escalas do urbanismo e da habitação.

A referida quadra Invictus, objeto de estudo deste artigo, localiza-se no Setor Nova Colina (Figura 1), na ocupação Dorothy Stang (Figura 2), dentro da cidade de Sobradinho - Distrito Federal. De acordo com Andrade et al (2018), estima-se que há cerca de 544 famílias em toda a ocupação, distribuídas em lotes unifamiliares e em habitações de madeirite, de caráter provisório. Na quadra Invictus (Figura 3, e 4) encontram-se cerca de 48 famílias nas mesmas condições. 


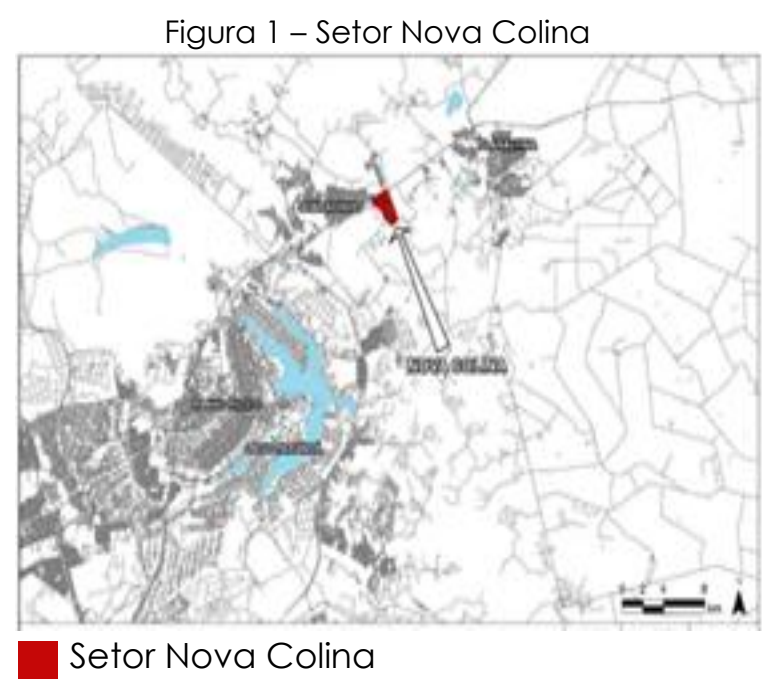

Fonte: Segeth, 2017

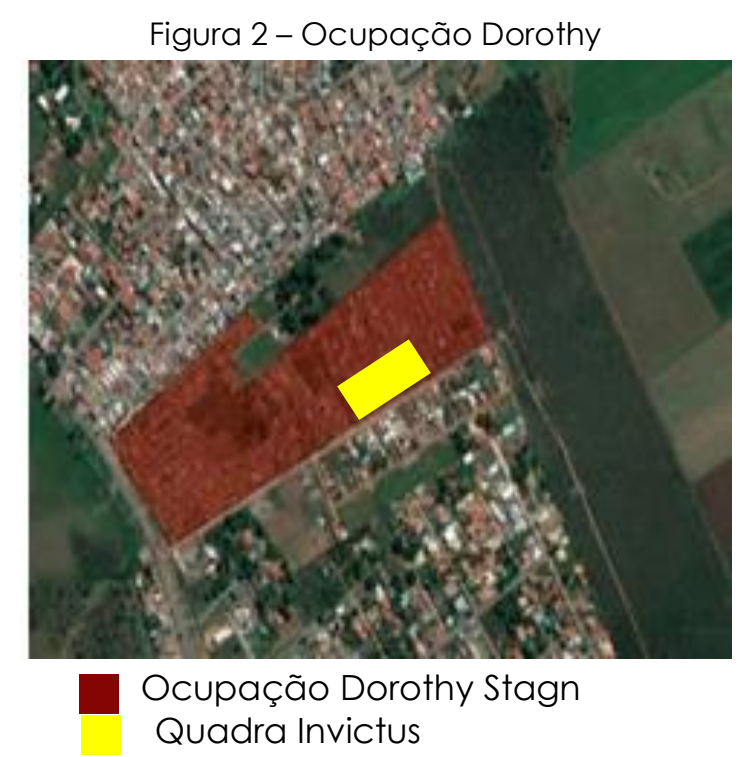

Fonte: Os autores, 2019
Figura 3 - Quadra Invictus

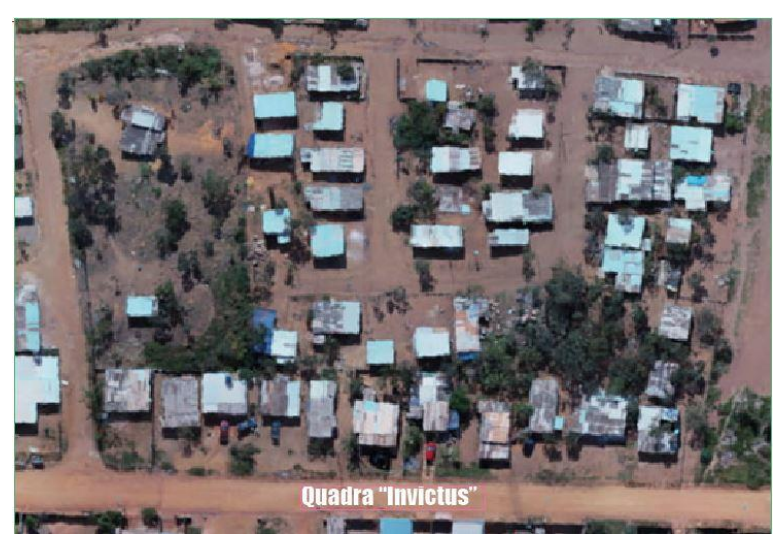

Fonte: Os autores, 2019
Figura 4 - Casa na quadra Invictus

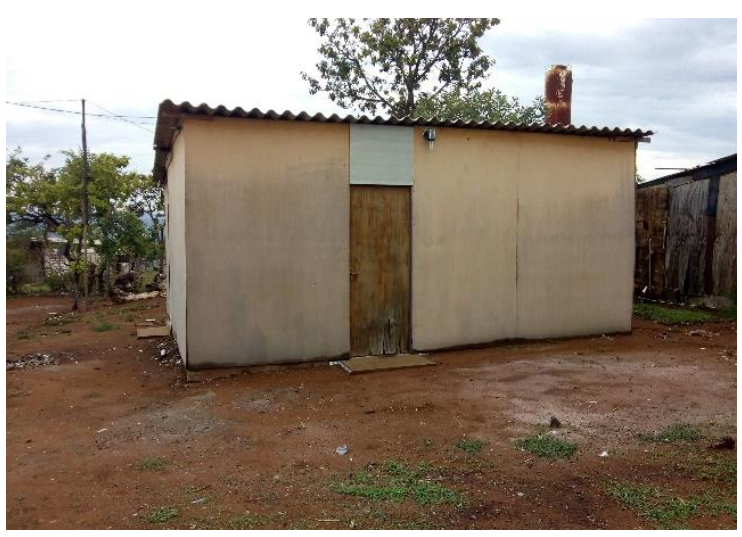

Fonte: Os autores, 2019

\section{OBJETIVO}

Visando a importância de se refletir sobre soluções bottom-up (de baixo para cima), em que a população tem importância fundamental nas decisões projetuais, este artigo objetiva relatar o processo de projeto participativo de habitação social para a quadra Invictus da ocupação Dorothy Stang, baseando-se nas Dimensões da Sustentabilidade de Andrade e Lemos (2015) (Figura 5) e com foco nas estratégias mais sustentáveis para o desenvolvimento de uma proposta de urbanismo e das respectivas tipologias habitacionais da quadra, desenvolvidas com base na participação da população local.

\section{METODOLOGIA}

A metodologia de Andrade e Lemos (2015) envolve conceitos de projeto relacionados a padrões espaciais emergentes que possam ser implementados de maneira sustentável e que sejam sistematizados em 4 dimensões: ambiental, social, cultural-afetiva e econômica. 0 intuito é avaliar um mesmo aspecto sob diferentes pontos de vista, buscando extrair dados de projeto que possam ser traduzidos em códigos geradores de processo de desenho urbano 
baseados nos padrões de Alexander et al. (1977). Andrade e Lemos (2015) afirmam que essa metodologia permite estabelecer um modo de projetar coerente entre as partes, de maneira que as propostas possam ser analisadas, avaliadas e revisitadas durante todo o processo de projeto e adotando, dentro do mesmo, características específicas da comunidade.

Figura 5 - Dimensões da Sustentabilidade de Andrade e Lemos (2015)

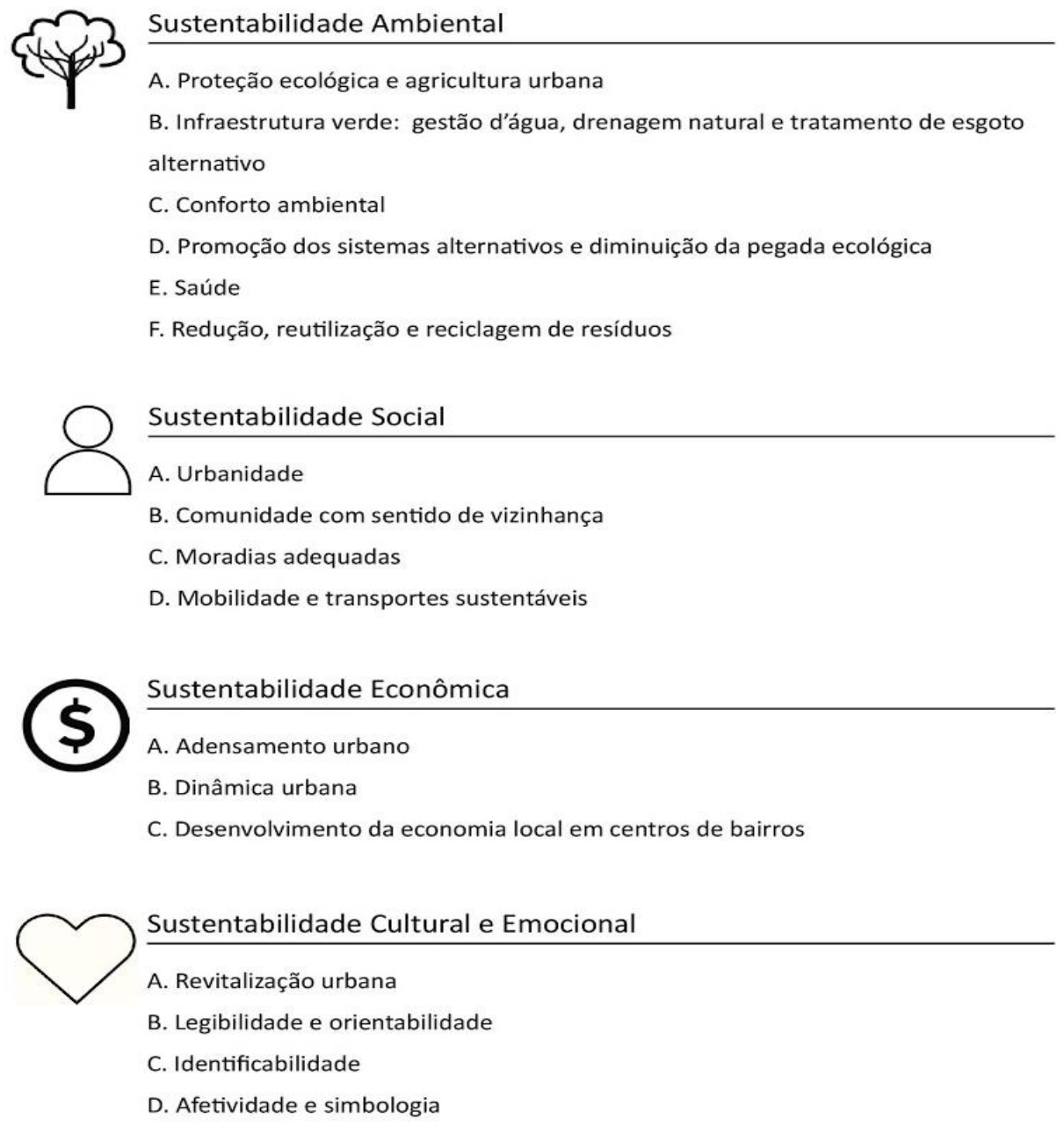

Fonte: Os autores, 2019

\subsection{As oficinas participativas}

Para fins didáticos, a metodologia acima descrita foi segmentada em oficinas participativas (Figuras 6 e 7) e aplicada à comunidade da quadra Invictus (Quadro 1), de maneira que se possa incentivar a participação ativa dos moradores nas decisões projetuais. A Oficina 1 tratou de conhecer a quadra e os problemas e potencialidades por meio de entrevistas e mapas afetivos com infográficos. A Oficina 2 tratou da sistematização de padrões identificados (Alexander et al 2018 e Andrade 2014) a partir dos infográficos. A Oficina 3 tratou de propostas alternativas para a Quadra Invictus e tipologias habitacionais 
Quadro 1 - Planejamento das oficinas

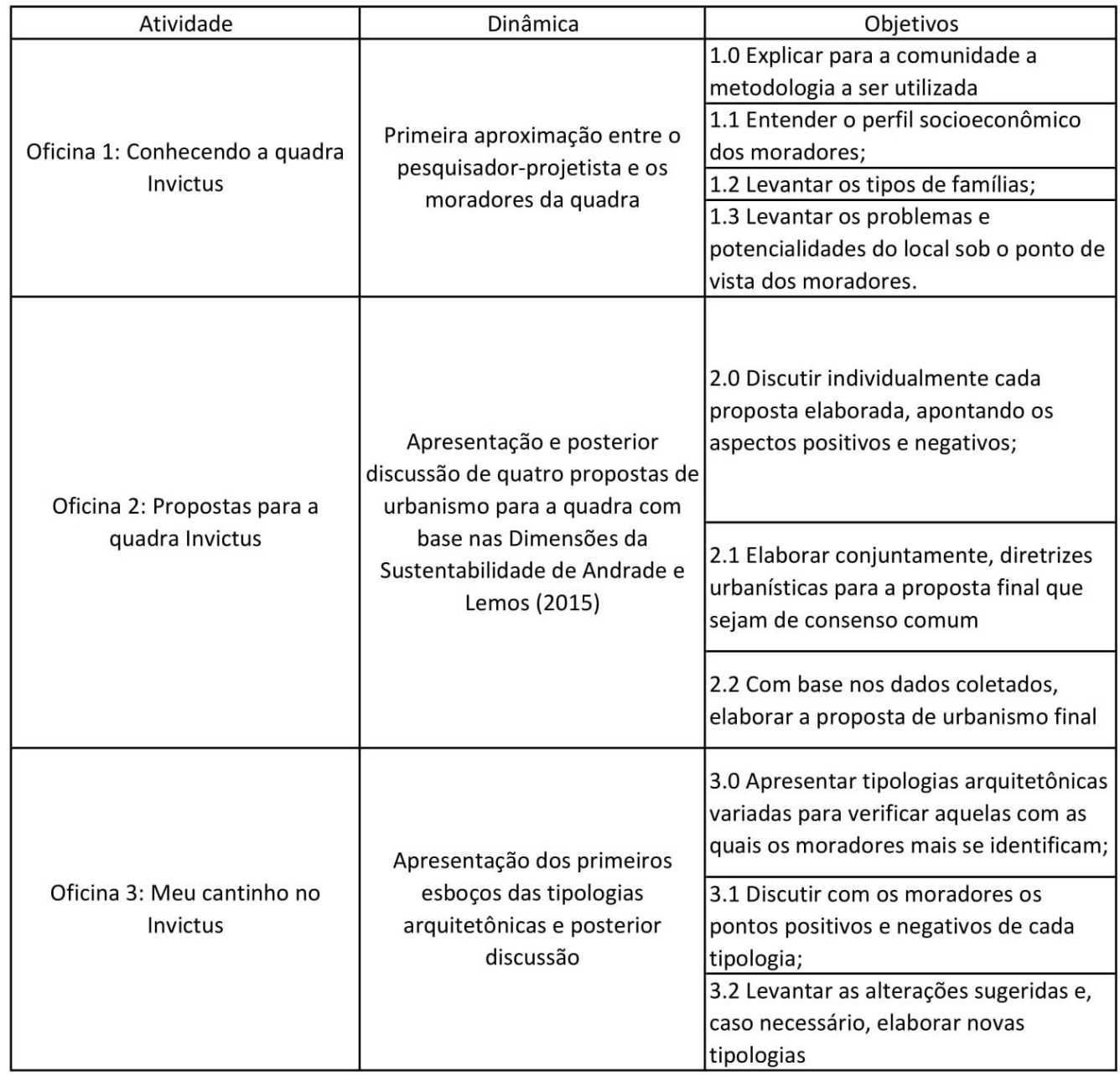

Fonte: Os autores, 2019

Figura 6: Oficina 1 - Conhecendo a quadra Invictus

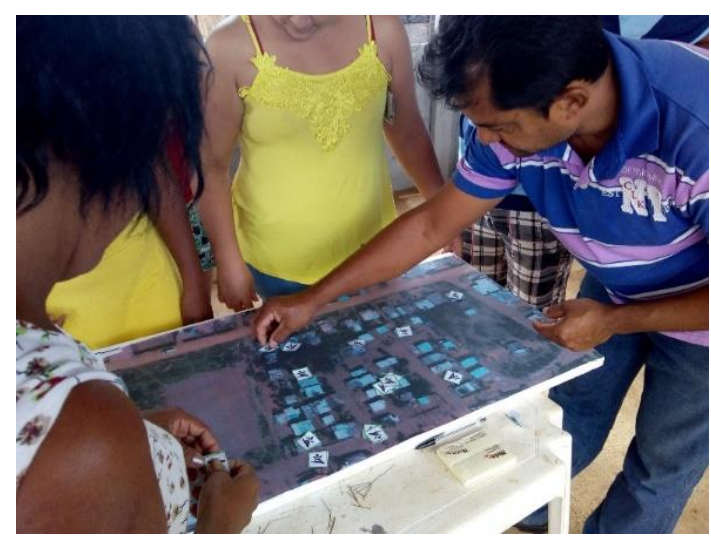

Fonte: Os autores, 2019
Figura 7 - A Praça das Pedras

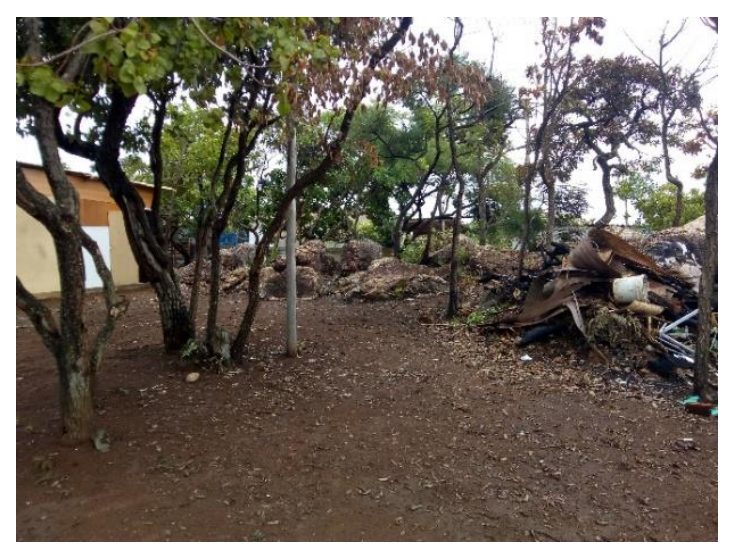

Fonte: Os autores, 2019 


\section{RESULTADOS}

\section{1 - As oficinas participativas}

A sistematização das dinâmicas de acordo com a metodologia de Andrade e Lemos (2015) possibilitou separar didaticamente os problemas e potencialidades sob as dimensões: ambiental, social, cultural-afetiva e econômica-; permitindo analisar cuidadosamente peculiaridades do local dentro de cada dimensão. O envolvimento da população também permitiu identificar particularidades como tipologias de famílias e residências, atividades econômicas locais e fluxos de pedestres e veículos. Os dados foram organizados nos Quadros $2,3,4$ e 5 .

Quadro 2 - Oficina 1, Dimensão Econômica

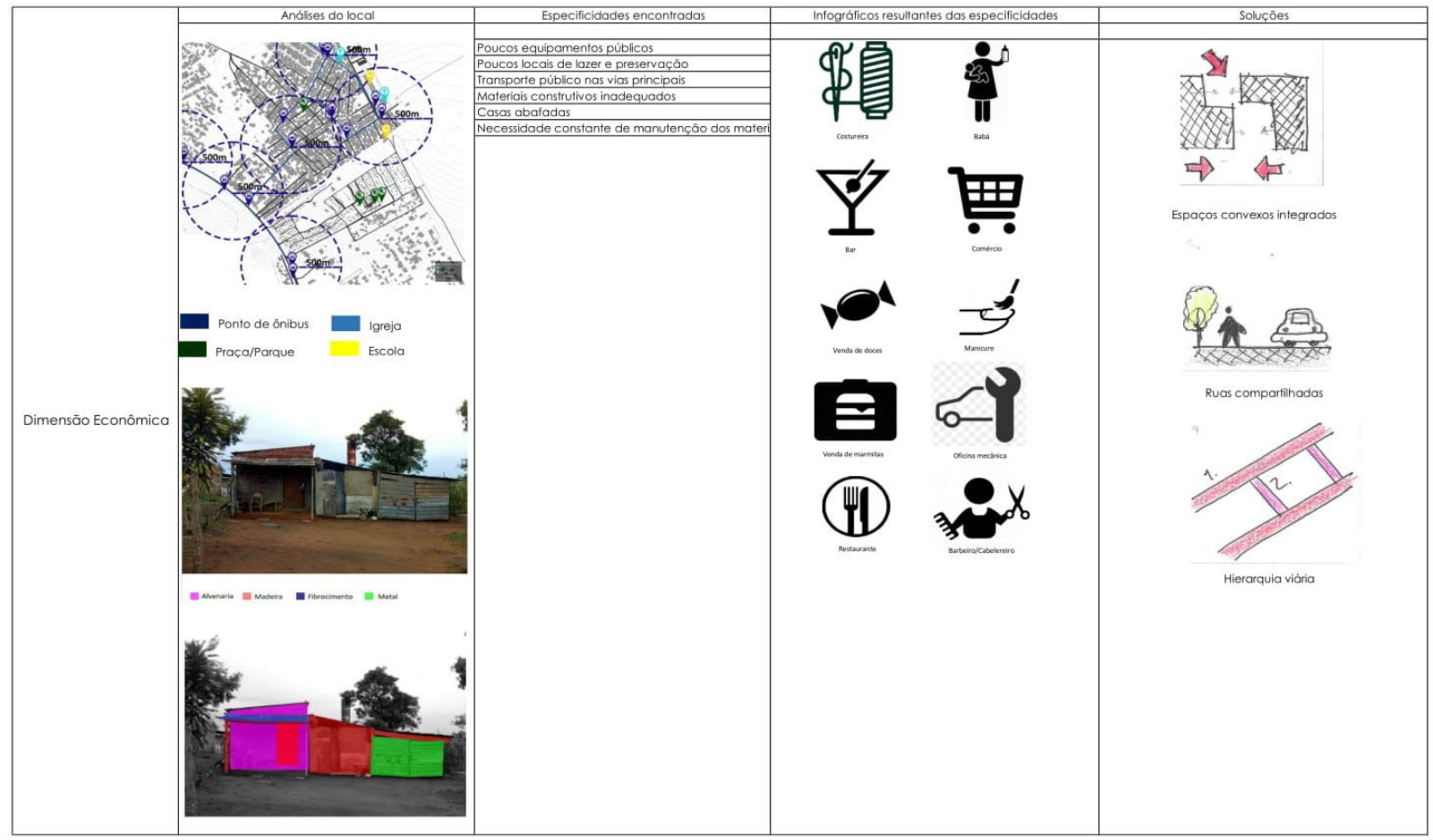

Fonte: Os autores, 2019 
Quadro 3 - Oficina 1, Dimensão Social

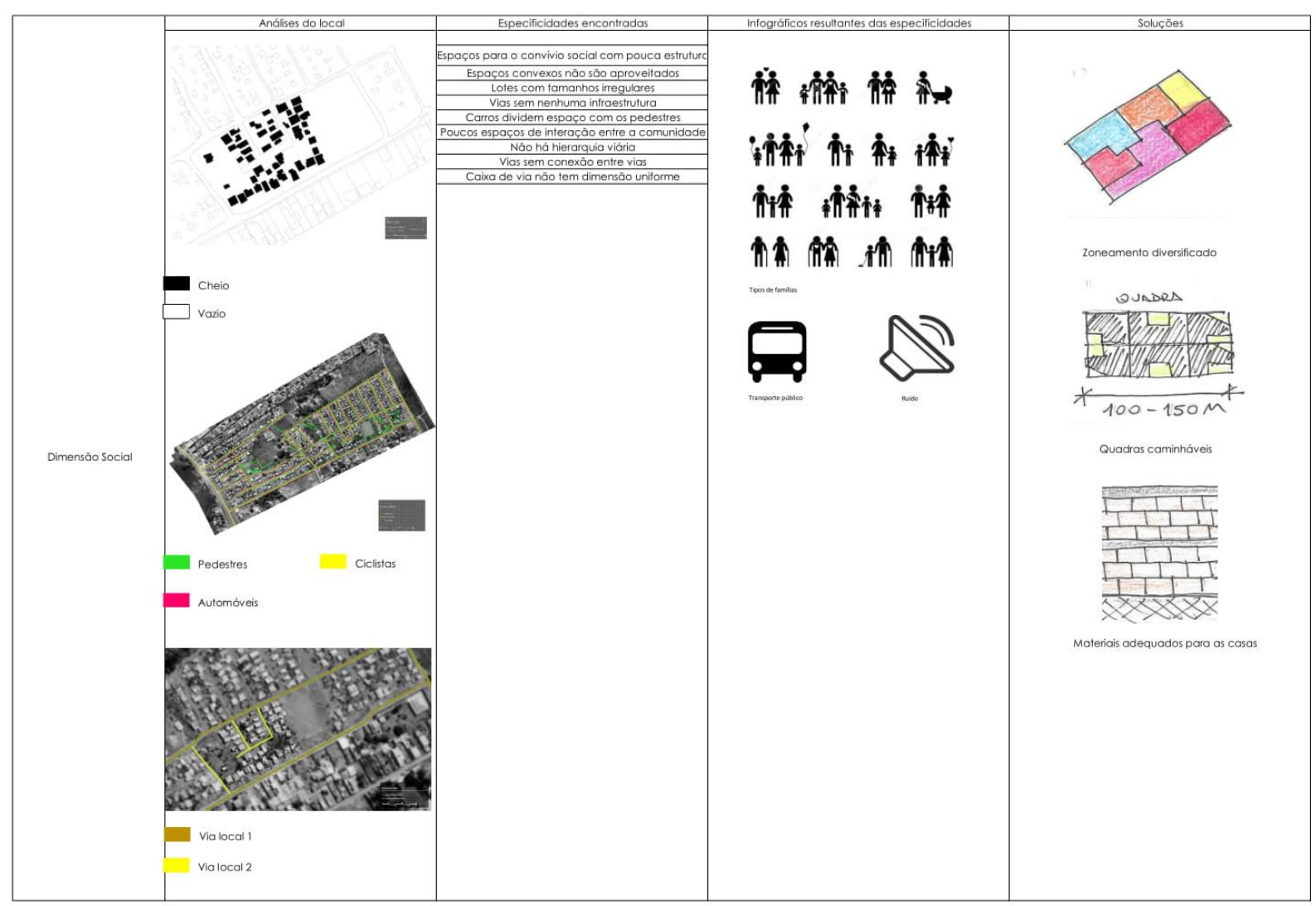

Fonte: Os autores, 2019

Quadro 4 - Oficina 1, Dimensão Cultural-Afetiva

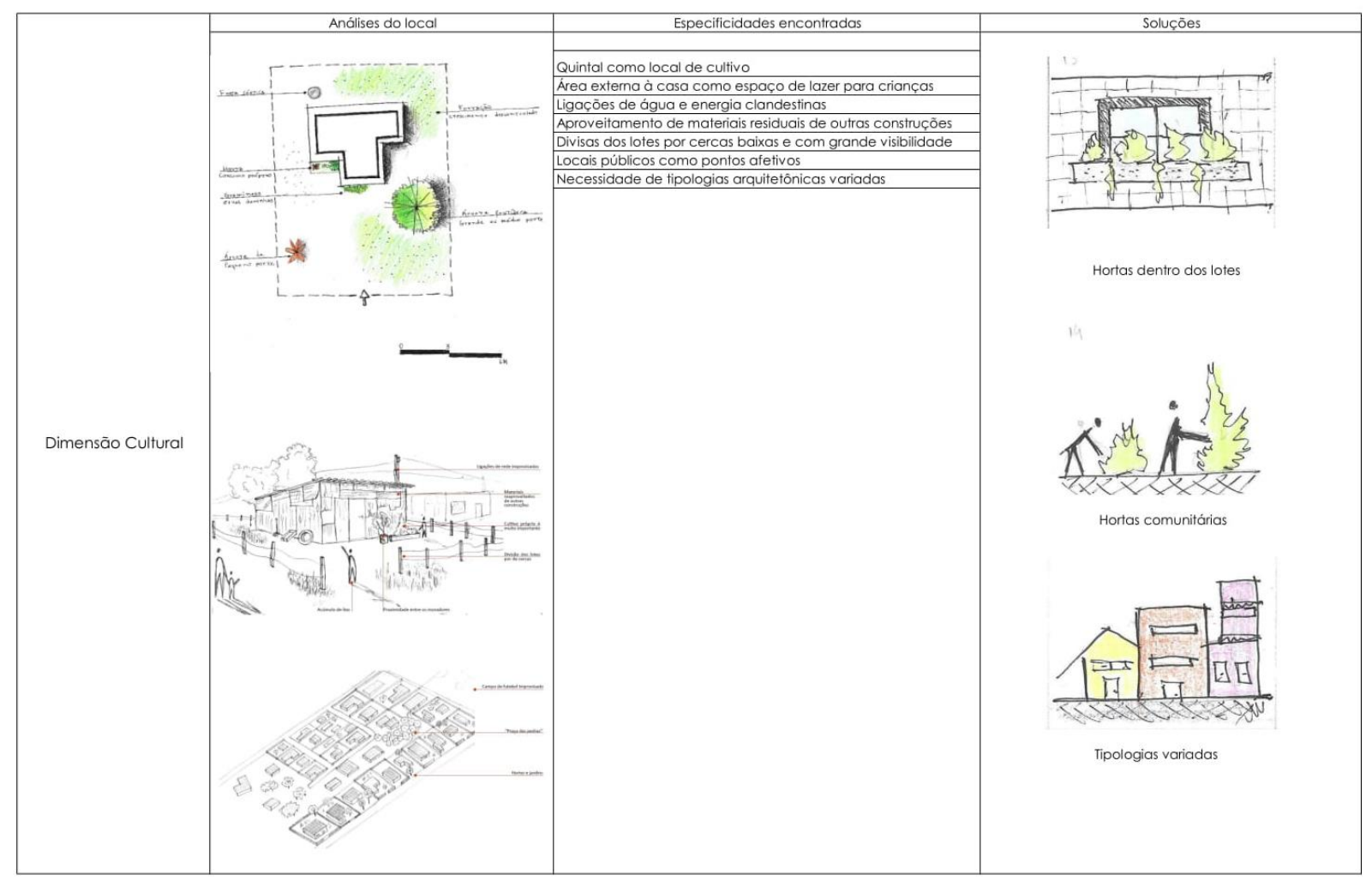

Fonte: Os autores, 2019 


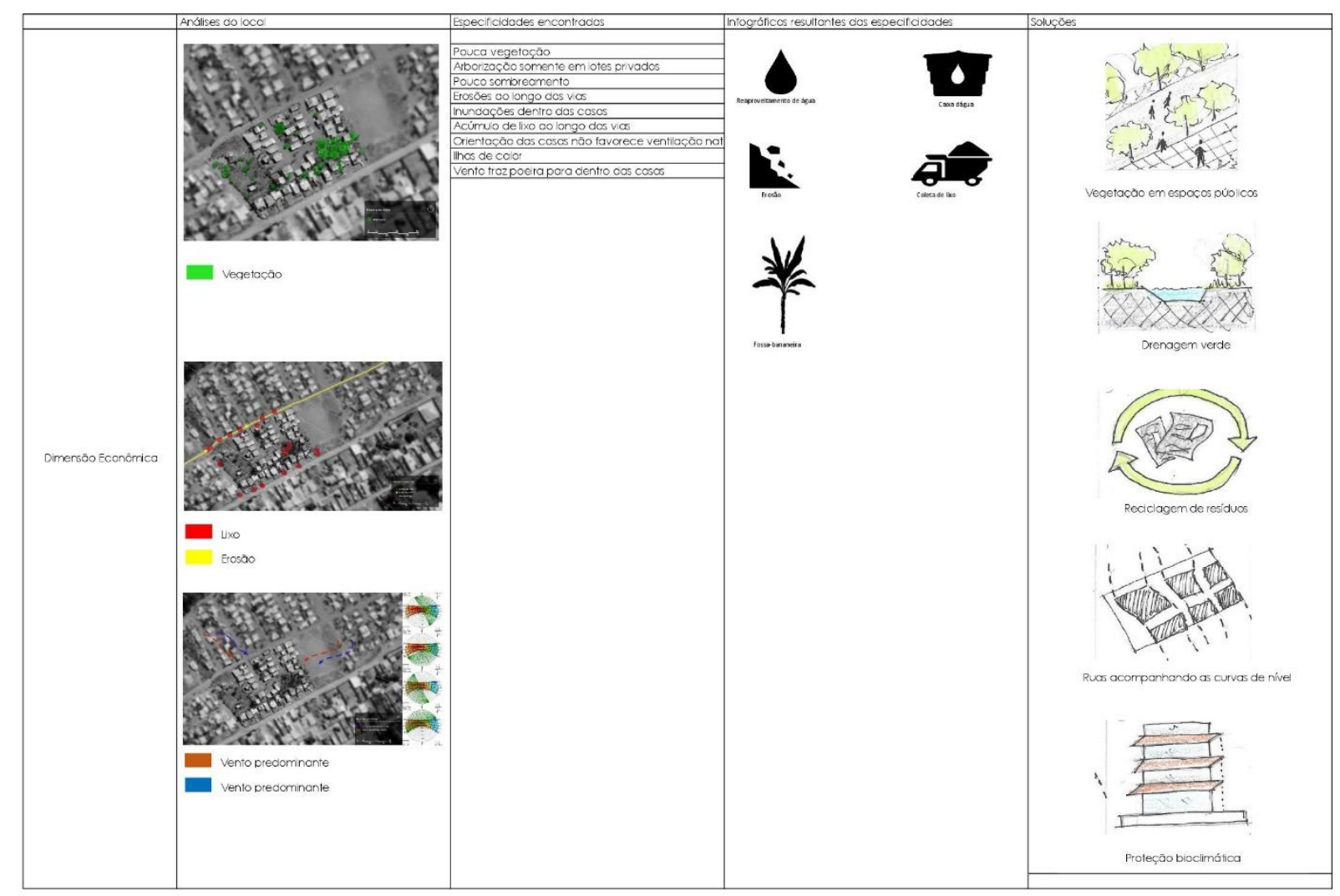

Fonte: Os autores, 2019

\section{2 - As propostas}

A síntese das propostas no projeto da quadra (Figura 8) priorizou o respeito ao caimento do terreno, à vegetação nativa e os pontos afetivos marcados pelos moradores. Ao mesmo tempo, também procurou-se adensar o espaço para criar maior diversidade social e propiciar o encontro das pessoas na rua por meio do alargamento das calçadas, da criação de quintais compartilhados e de tipologias voltadas para a rua, da criação de pequenos agrupamentos de lotes, defendidos por Alexander et al. (1977). Segundo Jacobs (2000), as casas voltadas para a rua podem oferecer maior sensação de segurança, além de fazer crescer o sentimento de comunidade e identificação das pessoas com o local. A criação de pequenas centralidades ajuda diminuir a quantidade de veículos circulando e também propicia o encontro dos vizinhos. 
Figura 8 - Croqui do projeto de urbanismo da quadra Invictus

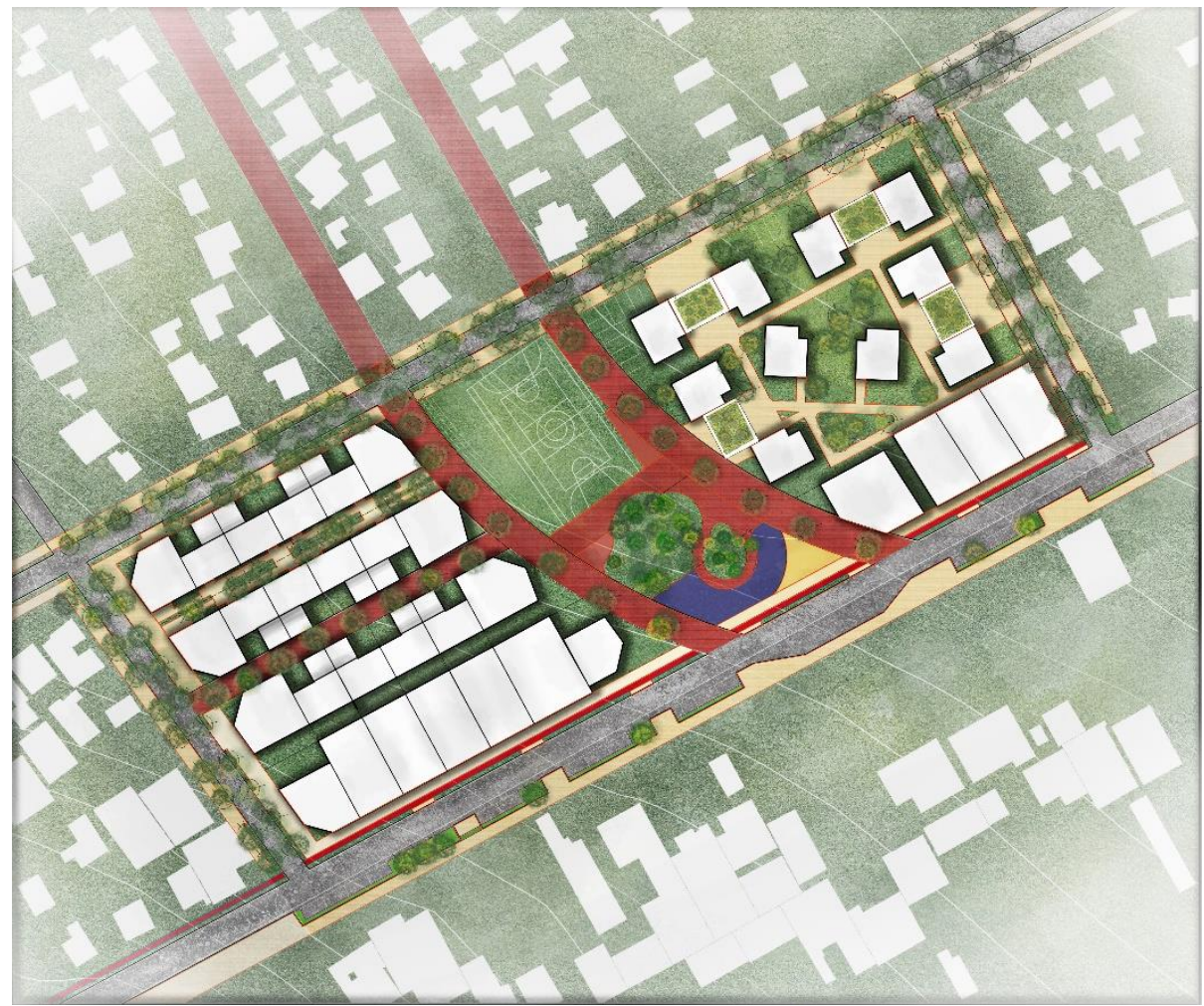

Fonte: Os autores, 2019

Na tipologia "A" pretendeu-se estimular o uso da rua ao reduzir o ponto cego da esquina por meio do chanfro arredondado na edificação e por meio da utilização do conceito de fachada ativa, em que o térreo é ocupado com lojas de testada curta, dando maior dinamicidade. A tipologia "B" foi pensada como duas casas sobrepostas no térreo e primeiro pavimento, com dois e três quartos, respectivamente; podendo atender a diferentes demandas. Os espaços livres e ajardinados foram pensados para o bom convívio dos moradores. A tipologia " $C$ " continua a usar o conceito de fachada ativa da tipologia anterior e, nos pavimentos superiores, oferece apartamentos com vãos de iluminação natural. A tipologia " $D$ " ainda está em fase de desenvolvimento, mas priorizará o compartilhamento dos espaços ajardinados externos à edificação, tornando-os locais públicos de passagem e de infiltração natural da água no solo (Quadro 6). 
Quadro 6 - Oficina 3, Propostas de Tipologias

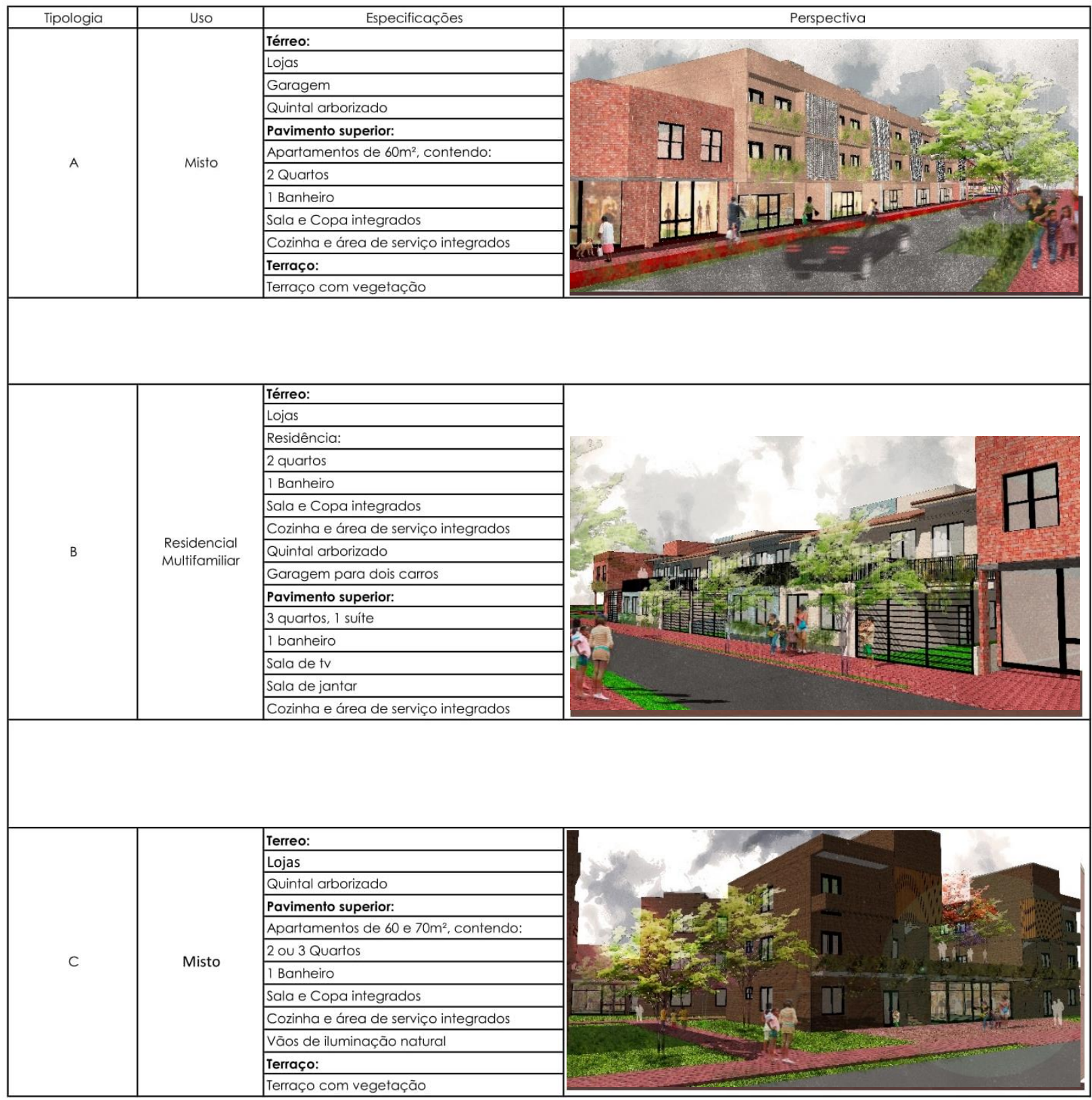

Fonte: Os autores, 2019

\section{5 - CONCLUSÕES}

Este trabalho demonstrou o processo de projeto participativo tendo como objeto a quadra Invictus da ocupação Dorothy Stang, no Distrito Federal. A experiência teve como personagens principais os moradores da quadra, que tiveram a oportunidade de expressar suas opiniões sobre a forma de morar que gostariam, tanto a nível do urbanismo da quadra quanto das tipologias arquitetônicas. Acredita-se que a participação popular nas decisões de projeto pode aumentar a garantia de permanência no local e evitar a gentrificação, uma vez que serão incorporadas no projeto características específicas daquela população, podendo aumentar o seu vínculo com o local.

Na primeira oficina, foi feito um levantamento geral sobre os problemas, potencialidades e demandas dos moradores para a quadra por meio de infográficos. Com base no levantamento e sistematização de padrões foram elaboradas quatro propostas de projeto urbanístico para a quadra de acordo com as Dimensões da Sustentabilidade de Andrade e 
Lemos (2015) e foram apresentadas na segunda oficina. Na terceira, foram apresentadas as primeiras ideias para as tipologias arquitetônicas. Foram discutidos os pontos que deveriam ser melhorados em cada uma e o projeto foi encaminhado para as propostas finais, ainda não concluídas.

Espera-se que este trabalho possa contribuir para o tema de Habitação Social e para os processos de projetos participativos na Arquitetura e Urbanismo.

\section{REFERÊNCIAS}

ALEXANDER, Christopher; ISHIKAWA Sara; Murray, SILVERSTEIN; JACOBSON, Max; FIKSDAHLKING, Ingrid; ANGEL, Shlomo. A Pattern Language. New York: Oxford University Press, 1977;

ANDRADE, Liza Maria Souza de. Conexão dos padrões espaciais dos ecossistemas urbanos: A construção de um método com enfoque transdisciplinar para o processo de desenho urbano sensível à água no nível da comunidade e da paisagem. 2014. 544 f. Tese (Doutorado) - Curso de Arquitetura e Urbanismo, Universidade de Brasília, Brasília, 2014. Disponível em: <http://repositorio.unb.br/handle/10482/18042>. Acesso em: 25 maio 2018.

ANDRADE, Liza Maria Souza de; LEMOS, Natália da Silva. Qualidade de projeto urbanístico: sustentabilidade e qualidade da forma urbana In: BLUMENSCHEIN, Raquel Naves; PEIXOTO, Elane Ribeiro; GUINANCIO, Cristiane. Avaliação de qualidade da habiłação de interesse social: projetos urbanístico e arquitetônico e qualidade construtiva. Brasília: Editora Unb, 2015.

BARROS, Raquel. Habitação coletiva: A inclusão de conceitos humanizadores no processo de projeto. São Paulo: Annablume, 2011;

DECANATO DE EXTENSÃO DA UNIVERSIDADE DE BRASÍLIA. Inscrição de proposta ao edital $\mathbf{n}^{\circ}$ 1/2017 - DEX/DPI. Brasília: Universidade de Brasília, 2017. Disponível em: < http://dex.unb.br/noticias/537-edital-programa-integrado-de-fomento-para-projetos-deinovacao-tecnologia-e-integracao-social>. Acesso em 07 jun. 2018.

JACOBS, Jane. Morte e Vida das grandes cidades. São Paulo: Martins Fontes, 2000. 